\title{
RE-CONSTRUYENDO LA EXPERIENCIA DE LA (PROPIA) DESAPARICIÓN:
}

\section{Reflexiones en torno a los relatos de sobrevivientes de los Centros Clandestinos de Detención (CCD) en la Argentina ${ }^{1}$}

Julieta Lampasona

Universidad de Buenos Aires, Argentina

http://dx.doi.org/10.5209/rev_NOMA.2015.v46.n2.51422

Resumen: En el presente estudio me propongo analizar las múltiples dimensiones que constituyen el testimonio de los sobrevivientes de los Centros Clandestinos de Detención (CCD) atendiendo, en particular, a las modalidades de emergencia de lo imaginario en los relatos de la (propia) desaparición, en sus yuxtaposiciones y/o tensiones con las dimensiones fácticas y/o materiales. Estas reflexiones apuntan a problematizar dicha experiencia como construcción que, encontrando su nudo constitutivo en la espacialidad del CCD, es moldeada al mismo tiempo por los procesos de rememoración.

Para ello, avanzaré en una articulación de consideraciones teóricas y el material empírico resultante del trabajo de campo -principalmente, entrevistas en profundidad y testimonios escritos-.

Palabras clave: Experiencia, desaparición, sobrevivientes, testimonio.

Abstract: In this article I propose to analize the multiple dimensions that testimony of Clandestine Detention Center's survivors involves. I will examine in particular the ways in which the imaginary dimension appears in the accounts of the own disappearance and its juxtapositions and tensions with the factual ones. This paper attempts to problematize the experience of own disappearance as a construction which has been produced in the spatiality of CDC but is also formed by remembrance processes.

In order to achieve our objective, I will articulate theoretical approaches and empirical materials gathered during fieldwork -mainly in-depth interviews and written testimonies-.

Keywords: Experience, disappearance, survivors, testimony.

\footnotetext{
${ }^{1}$ El presente estudio es resultado de una estancia de investigación en la Universität Konstanz (Alemania), en el marco del proyecto ERC "Narrativas del terror y la desaparición. Dimensiones fantásticas de la memoria colectiva de la dictadura en Argentina (1976-1983)" dirigido por la Dra. Kirsten Mahlke, durante los meses de junio y julio de 2013. Agradecemos las discusiones y contribuciones del equipo a la temática de estudio y, en particular, las sugerencias brindadas a este escrito por la Dra. Mahlke y la Lic. Rosario Figari Layús. Asimismo, se enmarca en nuestra tesis doctoral en curso, cuyo objetivo general consiste en indagar acerca de las inscripciones biográficas de la experiencia de la desaparición temporal y posterior sobrevida en sobrevivientes de los Centros Clandestinos de Detención (CCD) emplazados en nuestro país durante la última dictadura militar.

Advertimos que el abordaje se limita a problematizar sólo una de las modulaciones posibles de la tecnología de la desaparición, esta es, aquella referida a la desaparición/aparición del sujeto. Sobre el modo en que dicha tecnología se escinde en el par desaparición/eliminación y desaparición/aparición del sujeto, ver: Lampasona, 2013.
} 
"'The woman was testifying', he insisted, 'not to the number of the chimneys blown up, but to something else, more radical, more crucial: the reality of an unimaginable occurrence. One chimney blown up in Auschwitz was as incredible as four. The number mattered less than the fact of the occurrence. The event itself was almost inconceivable. The woman testified to an event that broke the all compelling frame of Auschwitz, where Jewish armed revolts just not happened, and had no place. She testified to the breakage of a framework. That was historical truth" (Laub, 1992: 69)

\section{Introducción}

La desaparición temporal y posterior sobrevida del sujeto supuso, en su despliegue, la articulación de las situaciones de persecución, secuestro, tortura, cautiverio y posterior liberación de los Centros Clandestinos de Detención $(C C D)^{2}$. Ahora, si bien esta serie se produjo en un espacio y tiempo determinados -el CCD-, tanto en las inscripciones psíquicas de lo traumático como en los procesos de rememoración y narración, sus límites se conjugan en otras temporalidades que invitan a repensar la experiencia de la (propia) desaparición desde nuevos pliegues. En el siguiente artículo, avanzaremos sobre dos dimensiones de la violencia vivida -material/"objetiva" e imaginaria ${ }^{3}$ y los relatos que la enuncian, para analizar el modo en que confluyen, conjuntamente, en el proceso de (re)construcción de esta experiencia ${ }^{4}$. Proponemos, a modo de hipótesis, que la misma se moldea en un doble movimiento: como producción de la violencia material -deshumanizante y constitutiva- del CCD y como puesta en sentido, desde la rememoración y el discurso, por parte del sujeto. En todo caso, intentaremos analizar cómo ambas dimensiones, en su mixtura, confluyen en su modulación y (re)construcción, al tiempo que nos permiten asir la radicalidad de esta experiencia límite y sus persistencias en el presente ${ }^{5}$.

\footnotetext{
${ }^{2}$ Retomamos la noción de "serie" en la producción del detenido-desaparecido propuesta por Rousseaux (2007: 380) -secuestro clandestino-tortura-fusilamiento-ocultamiento de los cuerpos- y desagregada por Vega Martínez y Bertotti (2009) -selección, persecución, secuestro, cautiverio, tortura, muerte y ocultamiento del cuerpo-.

3 Como analizaremos, por "imaginario" no referimos a una "irrealidad" de lo evocado sino a una construcción subjetiva, creativa y afirmativa del sujeto en el proceso de lidiar-con, elaborar y recordar lo vivido. Nos apoyamos, para ello, en los desarrollos de Castoriadis [1975] 2003).

${ }^{4}$ La demarcación del prefijo "re" nos permite atender a diversas cuestiones simultáneamente: advertir que no se propone pensar esta experiencia como pura construcción (imaginaria) del/los sujetos, como así tampoco anclarla en la pura materialidad de la violencia que le da origen; por el contrario, buscaremos analizar su modulación en ese doble proceso de producción material de la violencia y reconstrucción a partir de su simbolización, puesta en sentido y rememoración.

Nuestro análisis encuentra su inspiración en diversas producciones académicas. Por un lado, los desarrollos del equipo dirigido por la Dra. Mahlke que, desde la idea de lo "fantástico" permiten abordar dimensiones de la desaparición que escapan a la materialidad objetiva de los procesos de exterminio y considerar, con ello, nuevas entradas analíticas a los procesos de simbolización y rememoración -para un mayor desarrollo, ver apartado IV-. Por otra parte, la tesis doctoral de Pamela Colombo (2013) en torno a la construcción del espacio de la desaparición constituye un antecedente ineludible. En el capítulo específico sobre el campo, la autora propone complementar el análisis de los procesos de deshumanización con un abordaje relativo al espacio como construcción, un espacio vivido por el sujeto
} 
Avanzaremos en la articulación de consideraciones teóricas y el material empírico resultante de nuestro trabajo de campo, conformado por la realización de entrevistas en profundidad a sobrevivientes de los $C C D^{6}$ y la recopilación de fuentes secundarias (testimonios orales y escritos). A continuación, problematizaremos la noción de "experiencia" para, desde allí, analizar los testimonios en función de las dos dimensiones referidas.

\section{Sobre la noción de experiencia}

En "La institución imaginaria de la sociedad. El imaginario social y la institución", Castoriadis ([1975] 2003) analiza la dimensión instituyente, creativa y potente del imaginario radical ${ }^{7}$. En tanto origen perpetuo de alteridad (Castoriadis, [1975] 2003, 2: 327), el imaginario opera como productor incesante de figuras e imágenes que, desde el mundo de la significación entendida esta como un haz (abierto) de remisiones ${ }^{8}$ (Ibíd: 291)-, configuran las instituciones que componen la realidad social. La misma -sostiene- se da a sí misma a partir del magma de significaciones imaginarias sociales. Ahora, lejos de aparecer como puro reflejo de la materialidad del mundo o, por el contrario, como pura escisión abstracta, las significaciones imaginarias se constituyen en una relación sui géneris -dialéctica, podríamos decir-con la realidad material: las "cosas" del mundo se instituyen en y por el mundo de las significaciones y, al mismo tiempo, estas son sólo posibles sobre la base de su soporte. En palabras del autor:

"La institución de la sociedad es lo que es y tal como en la medida en que 'materializa' un magma de significaciones imaginarias sociales, en referencia al cual y sólo en referencia al cual, tanto los individuos como los objetos pueden ser aprehendidos e incluso pueden simplemente existir; y este magma tampoco puede ser dicho separadamente de los individuos y de los objetos a los que da existencia. No tenemos aquí significaciones 'libremente destacables' de todo soporte material, puros polos de idealidad: por el contrario, sólo en y por el ser $y$ el ser-así de este 'soporte', las significaciones son y son tales como son" (Ibíd: 307 y 309).

En términos de nuestro abordaje, debemos advertir que no proponemos un eslabonamiento directo entre las instancias imaginarias emergentes en la evocación de lo vivido en el CCD y el concepto de imaginario en Castoriadis. Aquellas suponen, en su propia emergencia, una construcción representacional

víctima de la desaparición: al tiempo que este se les impone y niega -producto del tabicamiento-, los sujetos lo habitan y configuran.

6 Las entrevistas realizadas se configuran en historias de vida. Para su realización, mantenemos sucesivos encuentros - de acuerdo a la disponibilidad de los entrevistados y momentos propios del relatoen los que abordamos diferentes temáticas desde una perspectiva biográfica. En el primero de los encuentros realizamos la presentación de nuestro trabajo y objetivos generales y pautamos conjuntamente la dinámica que asumirán las entrevistas. De acuerdo a cada caso varía la cantidad de reuniones. La información relevada es sistematizada y analizada a partir de nuestra matriz de datos cualitativa.

7 En términos de la singularidad, este asumirá la forma de "imaginación radical" e "imaginario social" o "sociedad instituyente", productor de significaciones imaginarias sociales, en relación a lo histórico-social (Ibíd: 328).

8 Este "haz (abierto) de remisiones" niega todo sentido cerrado sobre sí y supone la posibilidad permanente de nuevos significados. 
y están, por ello, ya atravesadas por la lógica identitaria o de conjuntos ${ }^{9}$; sólo así es posible pensarlas y enunciarlas. Lo imaginario, por el contrario, es basamento del mundo representacional pero escapa siempre, por su propia definición, a una representación que lo torne asible; en el intento por abarcarlo, es "organizado" y "nombrado" desde las categorías instituidas por el lenguaje. Pese a estas advertencias, estos desarrollos son sustanciales puesto que traen al centro de la escena la dimensión instituyente, abierta y múltiple del cúmulo de significaciones imaginarias y, desde allí, permiten pensar también en la potencia creadora del sujeto y/o lo social.

En su artículo "Experiencia" Joan Scott ([1992] 2001) deconstruye los usos que la disciplina histórica ha dado a este concepto, incorporando al análisis la acción performativa del discurso. Así, desde una crítica a su uso como verdad evidente sobre la que se apoyaría el conocimiento y/o explicación científica -un algo ya dado que sería posible aprehender en la inmediatez del evento/acontecimiento histórico que lo moldea- la autora nos propone una inversión. Precisamente, sostiene, de lo que trata el conocimiento es de asir esa experiencia no ya como "cosa" evidente en sí misma, sino desde el proceso mismo que le ha dado forma, conocerla en su constituir-se, darle historicidad y analizar, con ello, sus propios efectos sociales, esto es, las identidades y subjetivaciones que ella misma produce:

"(...) la experiencia se convierte entonces no en el origen de nuestra explicación, no en la evidencia definitiva (porque ha sido vista o sentida) que fundamenta lo conocido, sino más bien en aquello que buscamos explicar, aquello acerca de lo cual se produce el conocimiento. Pensar de esa manera en la experiencia es darle historicidad, así como dar historicidad a las identidades que produce. Este modo de dar historicidad (...) implica un escrutinio crítico de todas las categorías explicatorias que han sido dadas por hecho, incluyendo la categoría de la 'experiencia'” (Scott, [1992] 2001: 49 y 50).

Lejos de constituir -tan sólo, decimos- una vivencia directa de un evento, que se daría al sujeto (y/o al conocimiento que busca aprehenderla), la experiencia emerge aquí como construcción discursiva que, en su propio despliegue, produce, moldea la subjetividad ${ }^{10}$. Desde este prisma, resulta necesario considerar el trípode conformado por la experiencia-decimos, como construcción-, el relato que la enuncia y moldea, como así también las formas de subjetivación que esas mismas modulaciones producen ${ }^{11}$.

En esta perspectiva se inscriben también los desarrollos de Van Alphen (1999), quien avanza sobre las vinculaciones entre discurso, experiencia y memoria para pensar la especificidad que a este respecto plantean las situaciones traumáticas -"experiencias fallidas" o "trauma", siguiendo al autor (Ibíd: 25)-. En términos generales, Van Alphen señala que no sería posible hablar de "experiencia traumática" pues lo que produce el trauma es, en efecto, la supresión de la experiencia en tanto ruptura con el discurso (Ibíd: 26); ante ello,

\footnotetext{
${ }^{9}$ Esta ordena, clasifica, nombra y establece con ello una realidad cerrada sobre sí que -aun cuando necesaria para el despliegue de la vida- niega, sistemáticamente, su propio hacer autoinstituyente ([1975] 2003, 2: 61).

${ }^{10} \mathrm{Si}$ bien no profundizaremos su lectura en este estudio, los desarrollos de Foucault (2007) resultan sustanciales para comprender el discurso como práctica social con efectos de verdad, en términos de las relaciones y subjetividades que produce y moldea.

${ }^{11}$ Los comentarios que la Dra. Valentina Salvi efectuara sobre otros avances de nuestra investigación doctoral resultaron sustanciales para esta digresión. Agradecemos sus aportes.
} 
resulta sustancial la conformación de estructuras de significación que permitan narrarla. Recuperando el trabajo de Scott, la experiencia no depende tan sólo del evento vivido sino del discurso que permita pensarla y enunciarla (1999: 24); con ello, no supone en sí misma algo que los sujetos tienen sino aquello que hacen y es ese mismo hacer el que produce efectos de verdad en términos de su propia subjetividad. Extremando el argumento, señala: "subjects are the effect of the discursive processing of their experiences" (Op. cit.: 25). En particular, y en línea con los estudios de memoria, Van Alphen advierte que la situación traumática trastoca las formas de simbolización; frente a ello, decíamos, resulta necesario construir nuevas modalidades discursivas y estructuras simbólicas que doten de sentido la vivencia límite e incluyan, así, la experiencia en el campo de la significación.

En el caso que nos convoca, la desaparición suspende el lenguaje (Gatti, 2008), rompe las estructuras de significación que instituían y tornaban asible el mundo. En términos de la singularidad, la situación traumática rompe el mundo simbólico (Puget y Kaës, 1991; Kaufman, 1998, entre otros), y enmudece al sujeto. A partir de ello, la construcción de una palabra que enuncie lo vivido requiere de un proceso de elaboración que permita inscribir el evento traumático en el lenguaje, que lo torne enunciable -siempre de manera inacabada, parcial, lacunar-. En ese proceso, el sujeto re-construye el campo de experiencia, inscribiéndose él mismo en lo acontecido. En función de estas consideraciones, volvamos a nuestras preguntas: ¿cómo es ese proceso constructivo en el caso específico de la desaparición y posterior sobrevida? ¿es posible anclar la experiencia en la pura materialidad deshumanizante del CCD? ¿Cómo incide el sujeto en su propia modulación? Para intentar responder estas preguntas, analizaremos a continuación las diferentes dimensiones emergentes en los relatos.

\section{La (propia) desaparición desde su horror constitutivo}

Cuando nos proponemos acercar a la experiencia concentracionaria, el horror nos enfrenta al terror de lo inimaginable. Los testimonios de los sobrevivientes, esas voces de los que han estado allí y son hoy quienes pueden dar cuenta de ese límite de lo posible, evocan la radicalidad constitutiva del espacio del CCD: la brutalidad de la tortura, las condiciones extremas de detención y el acecho de la muerte forman parte de un relato que intenta dar cuenta de ello. Algunos lo hacen con mayor profundidad, otros con referencias más esquivas y otros desde una voluntad explícita de no reponer el horror de lo vivido. Todos ellos han atravesado la experiencia liminal del campo y dan cuenta, como pueden, de ello. Esta dimensión de la violencia vivida, con su radicalidad extrema, ha sido objeto de análisis en el campo académico y resulta sustancial a nuestro abordaje; veamos sus modos de emergencia en los relatos.

En nuestro segundo encuentro, hacia mediados mayo de 2012, Carlos $^{12}$ hizo referencia a ciertos momentos de su cautiverio. A diferencia de otros entrevistados, esta constituía una de las primeras veces en las que hacía pública -o narraba a un otro- su experiencia. En septiembre del '78, a plena luz del día, fue secuestrado frente a su familia y otros testigos en un bar del barrio

\footnotetext{
${ }^{12}$ Por un acuerdo de confidencialidad, los nombres utilizados son ficticios.
} 
de Constitución. A partir de entonces permaneció desaparecido, aproximadamente, durante treinta y cinco días ${ }^{13}$. En el último tiempo, tras largos años de exilio y de haber regresado al país luego de que el EAAF identificara los restos de un íntimo amigo desaparecido en 1977, Carlos comenzó a contar su historia y fue así que brindó su testimonio por vez primera. En su relato, hace referencia al secuestro, junto con los momentos inmediatamente posteriores al ingreso al CCD y la situación de tortura:

“E: ¿Cómo fue? ¿Te sacaron, había un operativo montado?

R: Un operativo de muchos autos, había mucha gente. Eh... deben haber sido como unos... 3 ó 4 Falcon. Me metieron adentro de un Falcon, me dieron vuelta, eh, y me llevaron (...). Me Ilevaron ahí, bueno, eh... Sacaron, me sacaron fotos, por supuesto, con un, un reflector en la cara. (...)

[Ya en el CCD] E: ¿En ese momento te cruzaste...? ¿Pudiste percibir que había otros detenidos?

R: Sí, sí, sí. Sí, había otra gente, mujeres gritando... Porque te hacen un recorrido, así, medio psicológico: olor a quemado, olor a carne, eh..., gritos..., llantos, o sea... Lo primero que hacen: te desnudan, te desnudaban, o sea, te dejaban sin identidad...

(...) Y... después, bueno, empezó la... o sea..., empezó..., empezaron las secciones..., las sesiones de, de... de picana. (Retoma el ritmo, como enunciando) y..., y el volver a preguntarte, te dejaban descansar, te sentaban, había un silencio... No había nada..., no escuchabas nada... Y de pronto venía alguien y te..., te martillaba una pistola y hacía 'iclick!', y se iba... De pronto, como vos estabas con capucha no veías, entonces venía otro y te tiraba un trompazo en el medio de la trompa, te tiraba al diablo, te volvía a acomodar en una silla..., se iba... Venía otro y te decía '¡No, hablá!, porque sino, vistes, acá lo que pasa es que si... decí lo que sepas, vistes'... O sea, 'mirá, yo voy a ver si te consigo esto...', qué sé yo. O sea, era todo, eh, era todo, o sea, era una, era un... jalgo macabro era directamente eso!".

La narración se conforma a partir del relato minucioso de las secuencias y tormentos que dan lugar a una violencia extrema: operativo, autos, su detención, el ingreso al CCD, las fotos, los gritos y olores, y el propio desquicio de la sesión de tortura. Esa violencia material se compone entonces de una serie de procesos y situaciones que se articulan en el intento de darle sentido.

En su libro "Desaparecido, memorias de un cautiverio", Villani (2011) realiza un relato profundo y pormenorizado sobre su secuestro y cautiverio -que tuvo lugar en los CCD Club Atlético, El Banco, El Olimpo, Pozo de Quilmes y ESMA y duró casi cuatro años- para, hacia el último capítulo, trazar algunas reflexiones sobre la vida con posterioridad a la liberación y las inscripciones de dicha experiencia. En los primeros capítulos, se refiere a la tortura:

"[En relación al secuestro] Durante el viaje me patearon y me amenazaron verbalmente, aunque no lo tengo grabado como una experiencia física sino más bien como una vivencia terrorífica" (Villani y Reati, 2011: 38).

"A media mañana del segundo día tuve mi primera sesión de unas horas de tortura, seguida por otra un día después. (...) Antes de la segunda sesión de

\footnotetext{
${ }^{13}$ Según pudo reconstruir, el lugar de reclusión habría sido la ESMA.
} 
tortura me llevaron a una sala de interrogatorio que no era la misma donde habitualmente se torturaba. Se trataba de una habitación pequeña donde no estaba la "parrilla" o cama en que se acostaba al prisionero para atormentarlo. Allí me golpearon mucho con bastones de goma como los que usa la policía, hasta que terminé con todo el cuerpo -desde el cuello a la cintura-convertido en un solo moretón gigante. (...) Mientras me daban bastonazos me hacían preguntas pero, como no se conformaron con mis respuestas, en cierto momento alguien dijo: 'iBasta, a la parrilla!', y me llevaron al otro cuarto. Igual que el día anterior, me ataron a una superficie de metal que tenía una argolla en cada esquina. Con correas parecidas a las que se usan para las cortinas de enrollar, me aseguraron las muñecas y los tobillos a las argollas. Previamente habían mojado la plancha de metal y me arrojaron más agua sobre el cuerpo antes de comenzar a darme electricidad con la picana. (...) Cada shock eléctrico lo sentía como si fuera el último y no sabía si podría aguantar otro" (Villani y Reati, 2011: 44 a 46).

En nuestra entrevista a Mariana, las conversaciones en torno a su desaparición duraron varios encuentros. La entrevistada militaba en la Juventud Peronista cuando, en mayo de 1977 fue secuestrada y recluida en diferentes CCD de la Capital Federal. Tras su liberación permaneció bajo el régimen de libertad vigilada, logrando partir al exilio en 1981 y regresando al país luego de la restitución democrática. Así nos relataba parte de sus vivencias:

"[En relación a vejámenes propios del cautiverio] Pero... si bien eso es..., obviamente, no le hace bien a la dignidad de un ser humano estar sometido... a esa experiencia... No es lo mismo... que estar atado a la parrilla. No... Y yo te diría, es que peor... de que te torturen a vos, es escuchar cómo torturan a otro. Eso es... o sea, escuchar, después de que te torturan a vos, que torturan a otro... Eso es... la verdad... yo te diría que... en un punto, no sé... ¡Lo peor que te puede pasar! Porque..., porque no podés evitar ponerte en el lugar del otro, $y . .$. iEs tremendo! La verdad que... iesa experiencia es realmente tremenda!

Yo me pasé muchas noches... Ilorando, escuchando cómo torturaban a otro.

(...) También las horas posteriores a la tortura son... Uno queda en una situación como si fuera un animalito asustado, ¿no? Que todo te... itodo te sobresalta! Entonces estás... temblando permanentemente. Entonces, se acerca alguien... a tu puerta y te sobresaltás" (Cuarto encuentro, junio de 2011).

Lo extremo de las condiciones de cautiverio, lo insoportable de la tortura a los otros compañeros y la vulnerabilidad absoluta que produce la tortura en el propio cuerpo aparecen en el conjunto de testimonios. Para comprenderlos resulta sustancial retomar los desarrollos de Calveiro ([1998] 2004), quien avanza sobre los procesos de deshumanización que conformaron uno de los nudos constitutivos del poder desaparecedor. Precisamente, es en función de estos desarrollos que podemos acercarnos a la espacialidad de los CCD como ámbitos que apuntaron a la desinvestidura del sujeto respecto de aquello que constituía su humanidad, socialidad e historicidad. Desde el momento del secuestro el detenido era sometido a un conjunto de prácticas y situaciones que apuntaban a despojarlo de su identidad y de su mundo de pertenencia; a esto -como así también a la obtención de información- coadyuvaron la tortura, 
la supresión del nombre, el tabicamiento, la posibilidad constante de la muerte y el desquicio constitutivo del espacio concentracionario ${ }^{14}$. No obstante, estos procesos no pueden pensarse en sentido acabado pues, como señala la autora, ese poder que se pretendía total se ha encontrado, de una u otra manera, con formas de fuga y/o resistencias ${ }^{15}$.

Conjuntamente con esta materialidad brutal de la violencia, los testimonios dan cuenta también de una "cotidianeidad" posible. "Cotidianeidad" que, conformada en y por ese avasallamiento y el despliegue de la crueldad, da cuenta en la misma narración de su carácter precario, frágil, doloroso, en el límite; una "cotidianeidad" agónica, constituida en y lindante -siempre- con el horror. Así, comienzan a narrarse rutinas, momentos de encuentro y formas de solidaridad que, aunque precarios e incluso esporádicos, fueron generando la posibilidad de sobrellevar ese avasallamiento y tormento permanente, de sobrevivir allí dentro aunque sea un día más; al menos, hasta el momento último donde se determinara la "suerte" del detenido, esto es, la muerte y desaparición del cuerpo -mayoritariamente- o la vida -en algunos casos- ${ }^{16}$.

Horror y "cotidianeidad" constituyen, entonces, esa liminalidad propia de estos espacios. $Y$ es esa confluencia lo que fue configurando aquello propio de lo siniestro como encuentro de lo "familiar", lo conocido, y el mundo de lo ominoso, lo terrorífico. Lo siniestro, plasmado crudamente en esa yuxtaposición del horror propio del CCD con una vida posible a su interior ${ }^{17}$. En este sentido, señala Gatti:

"Los chupaderos (...) son el operador de la devastación, el dispositivo sin el que esta maquinaria hubiese sido imposible. Ahí sucedió todo. Ahí sucedió la catástrofe. Son espacios cuando menos extraños: oyendo a quienes los (mal)vivieron da la impresión de que se encuentran en mundos paralelos al nuestro, ajenos a nuestra normalidad. Que están reglamentados por términos que son del orden de lo clandestino, de lo excepcional, de lo oscuro, del secreto (...). En él la regla, esa que reglamenta la normalidad de las cosas, se

\footnotetext{
14 Los desarrollos de Agamben (2000 y 2002) sobre la experiencia de los lager nazis abordan esas espacialidades donde "todo es verdaderamente posible" (Agamben, 2002: 34). Allí, el sujeto era desanclado (o pretendía serlo, sostenemos) de ese mundo político-social que lo constituía.

15 "Todas las formas de fuga de que dan cuenta los distintos testimonios: el escape personal a las situaciones más dolorosas; la risa que permite recuperar la humanidad de desaparecido y desaparecedor, reinstalando cierto equilibrio; el engaño que invierte el control de la situación; la conspiración que restablece los lazos de solidaridad, cooperación y resistencia y la fuga que rompe de un golpe con el secuestro y la desaparición, son todas formas de lo que he llamado líneas de fuga y resistencia. Todas ellas muestran que dentro del campo, a pesar del fantástico poder de aniquilamiento que se despliega, el hombre encuentra resquicios" (Calveiro, [1998] 2004: 127).

${ }^{16}$ En el estudio referido anteriormente y en aproximaciones previas, Colombo busca dar cuenta de esa "cotidianeidad" desde la idea misma del espacio de desaparición como espacio construido; un espacio configurado en y por el horror que, al mismo tiempo que negado/vedado/impuesto al sujeto, es moldeado en cierta forma o, más bien, imaginado/construido por aquel que lo atraviesa. Ver: Colombo, 2011 y 2013. Por su parte, esa "cotidianeidad" puede leerse también en el abordaje de Feld (2010) sobre el caso específico de la ESMA; allí, como analiza la autora, la "vida cotidiana" se entretejía entre torturas, cautiverio, espacios compartimentados que eran no obstante ámbitos de circulación de los secuestrados siempre, en función de la voluntad de los represores-, intercambios de información entre secuestrados y trabajo esclavo -para el caso de los miembros del denominado "Staff"-, entre otros. Todo ello, sostiene Feld, corría los límites y/o tramaba otros nuevos, más difusos, al interior del propio CCD como también en su relación con el afuera.

17 Sobre lo siniestro, ver: Freud, ([1919] 2006). Esta noción de lo siniestro es analizada también por Feld (2014) en su estudio sobre la ESMA, donde lo ominoso asumía una particularidad específica en el entrecruzamiento de lo horroroso de la tortura y el cautiverio junto, entre otras, con modalidades de trabajo esclavo a las que eran sometidos parte de los detenidos.
} 
convierte en negación-de-la-regla. Es un espacio en off en el que malviven, malmueren, los chupados (...) Un espacio torvo; un lugar denominado por una lógica absurda, en el que la cotidianeidad transcurre en 'los confines más subterráneos de la crueldad y la locura' (CONADEP, 1987: 59)" (Gatti, 2008: 56-58).

\section{La (propia) desaparición desde un "haz de remisiones"}

Al adentrarnos en las entrevistas y testimonios, este anclaje material de la violencia se complementa y tensiona, al mismo tiempo, con otras dimensiones de la palabra de los sobrevivientes. A su análisis nos abocaremos en este apartado.

En su libro "Preso sin nombre, celda sin número", Timerman relata su desaparición -ocurrida a mediados de abril de 1977- junto con consideraciones acerca del contexto político y algunas reflexiones en torno a los momentos posteriores a su liberación. En esa narración, va reconstruyendo una genealogía de largo plazo, la de su persecución como parte de un colectivo más amplio -el pueblo judío-, ya avasallado por el genocidio nazi. En las primeras páginas del texto, el autor describe la celda en la que se encuentra detenido: el alto, las paredes, la temperatura del piso, la falta de instalaciones sanitarias, una puerta con una mirilla hacia afuera y él mismo que, ante el descuido del guardia, logra mirar por la rendija y sentirse -aunque fuera por unos segundos- libre. Es en ese momento que aparece otro detenido; mujer u hombre, no lo sabemos, pero cuya presencia se torna manifiesta a través de su mirada. Y es así entonces que en la evocación de ese otro -con atributos reales o imaginados, poco importa-, y casi a modo inaugural, comienza a dar cuenta de su secuestro y el posterior cautiverio:

"Y entonces tengo que hablar de ti, de esa larga noche que pasamos juntos, en que fuiste mi hermano, mi padre, mi hijo, mi amigo. ¿O eras una mujer? (...) Eras un ojo, pero recuerdas esa noche, ¿no es cierto? Porque me dijeron que habías muerto, que eras débil del corazón y no aguantaste la "máquina", pero no me dijeron si eras hombre o mujer. $Y$, sin embargo, ¿cómo puedes haber muerto, si esa noche fue cuando derrotamos a la muerte?

(...) Recuerdo perfectamente que parpadeabas, y ese aluvión de movimientos demostraba sin duda alguna que yo no era el último ser humano sobre la Tierra en un Universo de guardianes torturadores. (...) comprendí que recreabas la gran aventura humana del encuentro y el desencuentro. $Y$ entonces jugué contigo. A veces volvíamos a la mirilla al mismo tiempo, y era tan sólido el sentimiento de triunfo, que parecíamos inmortales. Éramos inmortales.

(...) Yo entendí que me estabas consolando, y comencé a llorar. En silencio, claro. (...) tú viste que lloraba, ¿verdad?, lo viste sí. Me hizo bien llorar ante ti (...) Tú me enseñaste, esa noche, que podíamos ser Compañeros del Llanto.

No sé por qué, pero estoy seguro que eres -¿eras?- un hombre joven, de mediana estatura. Digamos 35 años, con un gran sentido del humor. (...) Tenías un corazón fuerte, generoso, valiente" (Timerman, 1981: 6 y 7).

Y más adelante, continúa: 
(...) Amigo mío, hermano; ¡cuánto aprendí de ti esa noche! (...) Comprendí muy bien que me decías que la ternura volvería. (...) ¿Porque la ternura consuela a la persona que ya está resignada? Y tú seguramente necesitabas que te consolara. No, no lo entendí. ¿Entonces, hermano mío, mi amigo, mi Compañero del Llanto, entonces ya sabías y estabas resignado? Pero amigo, hermano, si es cierto, ¿por qué y para quién estoy diciendo todas estas sandeces? ¿Estoy hablando conmigo mismo, como un estúpido? ¿No hay ningún ojo que me mira?" (Timerman, 1981: 9).

Ese otro estaba ahí y las referencias a su muerte -brindadas por los represores- parecen "certificarlo". Pero, ¿quién y cómo era? ¿Es que estaba efectivamente allí, acompañando? ¿Es que "jugaba", contenía, devolvía la mirada? El mismo Timerman se lo pregunta, pero no podemos saberlo; nunca han hablado ni se han visto completamente. En todo caso, no es eso lo que importa sino los efectos de verdad/realidad que produce, esto es, el modo en que ese otro coadyuva en la puesta en sentido del cautiverio y que, junto con la atribución de gestualidades y actitudes de solidaridad y acompañamiento, da cobijo a ese sujeto en los momentos posteriores a su secuestro y permite, en su evocación, inaugurar el relato de la (propia) desaparición.

Casi 20 años después ${ }^{18}$, en el libro "Ese infierno. Conversaciones de cinco mujeres sobrevivientes de la ESMA", las autoras recorren diferentes temáticas que coadyuvan en la comprensión y elaboración colectiva de su paso por ese CCD. En diferentes momentos y circunstancias, cada una de ellas fue secuestrada y recluida allí, permaneciendo desaparecidas por meses e incluso años. En conversaciones específicas relativas a la situación de tortura, conversan en torno a cierto desdoblamiento psíquico respecto del cuerpo: un "desdoblamiento" en el tiempo -un sujeto que, desde el presente, rememora y vuelve sobre la situación de tormento y la revive casi en su literalidad- y/o un "desdoblamiento" - ¿"paranormal"?- en la figura de lo que podría pensarse como un "imposible", esto es, la separación del sujeto respecto de sí mismo, de su propio cuerpo, en el momento mismo de la tortura ${ }^{19}$ :

"Munú: Yo hasta el día de hoy, sigo viéndome atada en una cama de metal, el agua sobre el cuerpo desnudo para que la corriente haga más efecto... Me veo, pero no puedo vivenciar el dolor físico.

\footnotetext{
18 Las producciones testimoniales de sobrevivientes de los CCD argentinos han sido profusas. Sin embargo, de acuerdo a los momentos socio-memoriales (esto es, los años '80, '90 y/o 2000) y los lugares de publicación (en el país o el exterior, durante el período de exilio), no han tenido la misma circulación en Argentina. En términos generales, podemos decir que aquellos libros publicados hasta comienzos de los años '90, en el exterior, no tuvieron la repercusión de aquellos de finales de esa década y la siguiente que fueron publicados en la Argentina. Entre unos y otros, como a modo de bisagra y palabra legitimadora, encontramos la obra de Calveiro ([1998] 2004).

19 El problema del desdoblamiento subjetivo puede rastrearse ya en los primeros estudios sobre la experiencia nazi. Particularmente, el análisis de Bettelheim (1943: 421) sobre el proceso de transformación al que se ven sometidos los prisioneros de los campos desde el momento mismo de su detención, y en relación a su propio comportamiento como prisionero, el autor remite a cierto dislocamiento que se produce a nivel del individuo en tanto aquel que observa lo que sucede y/o aquel a quien las cosas efectivamente le suceden. Ese dislocamiento será retomado por Mahlke (2014) en su análisis sobre los testimonios de sobrevivientes de los campos nazis y los CCD argentinos; allí se propone observar las distorsiones temporo-espaciales que suscita el terror. En este recupero de la idea de un dislocamiento, la autora repara en el modo en que las distancias producidas entre el mundo de lo conocido y los eventos a los que los sujetos son sometidos configuran una realidad inolvidable al tiempo que irreal (Ibíd., 2014: 111) e imponen a la narración de la experiencia limite características propias del lenguaje fantástico (Ibíd., 2014: 113).
} 
Liliana: (...) Lo que a mí me pasa es que reconstruyo la escena y puedo mirarla desde afuera, y me meto dentro y reproduzco absolutamente todas las sensaciones (...) pero tengo un dolor muy atenuado del dolor físico (...).

Miriam: A mí me generó una sensación de desdoblamiento, yo salía de mi cuerpo y lo miraba desde afuera. (...)

Liliana: Sí, te disociás" (Actis, et. al., 2001: 74).

En nuestra entrevista realizada a una de las autoras, ella misma señalaba:

"O sea, la corriente eléctrica es una cosa... ies tremenda! O sea... Es muy insoportable. (Recupera el tono) Entonces, en un punto, eso era lo que más me jodía. Pero hay como una cosa que... varias personas... dijeron haber... sentido, y no sé con qué tendrá que ver, si es un fenómeno paranormal o psicológico, que llegaba un punto, un umbral de dolor, en el que yo era como que me despegaba de mi cuerpo y me miraba desde arriba. iY no soy la única a la que le pasó! (Con un tono de asombro) iMucha gente relata lo mismo! $O$ sea, de mis compañeras de... del libro, hay por lo menos una más que relata lo mismo, y después, en algunos testimonios, yo escuché el mismo relato. No sé con qué tiene que ver. Es como que llegás a un umbral de dolor después del cual... es como... Debe ser como un mecanismo de defensa" (Cuarto encuentro, 10/06/2011).

El momento de la tortura, ese instante de avasallamiento más absoluto del sujeto, produce -casi a modo de fuga, diría Calveiro- una evasión, un irse fuera de sí que permitiera tolerar el dolor inimaginable. $Y$ es en este punto donde, nuevamente, interesa considerar el modo en que la instancia de lo imaginario acaso en estrecha vinculación con el género fantástico ${ }^{20}$ - confluye en la representación de la situación extrema: esa separación asume para la entrevistada un carácter de realidad constitutiva que configura, en su evocación, la situación misma de tortura. Poco importa que el sujeto (no) pueda, en efecto, salirse de sí y evadir con ello ese dolor supremo, pues como vemos ese desdoblamiento -aún cuando fuese imaginario- tiene efectos de verdad: en el momento mismo de la tortura parece haber coadyuvado para tolerarla, en el momento de la evocación confluye en la configuración misma de

\footnotetext{
${ }^{20}$ A partir de nuestra aproximación a las lecturas y debates del equipo de investigación "Narrativas del terror y la desaparición", hemos podido comprender que el estudio de lo fantástico ha sido abordado desde múltiples campos disciplinarios (Jackson, 1981; Todorov, 2006, entre otros), permitiendo desplazar el abordaje desde la dimensión "ficcional" hacia las instancias psíquica y social. Retomando a Todorov, lo fantástico remitiría a aquello sobrenatural que irrumpe inesperadamente y resulta imposible de aprehender de manera racional; como señala Pérez (2013a), el género asume en su seno el problema de la espectralidad: espectros, fantasmas, muertos que se hacen presentes, objetos inanimados que cobran vida, lo atraviesan y constituyen.

En particular, los estudios desarrollados por el equipo de la Universidad de Konstanz permiten precisar sus vinculaciones con los efectos traumáticos de los procesos de violencia social en la Argentina y el acecho de lo fantasmático: lo fantástico emerge "como modo de decir lo indecible" que se intersecta con lo terrorífico en la figura paradigmática del desaparecido (Mahlke, 2009) remitiendo, con ello, a "la dimensión espectral de la memoria en la Argentina" (Mahlke, et. al., 2012). En este prisma, las líneas de investigación de sus integrantes han avanzado sobre las narrativas en torno a los ex CCD devenidos Espacios para la Memoria (Schindel, 2013), las producciones teatrales de la posdictadura (Pérez, 2013a y b), los efectos sociales de la impunidad y la construcción de justicia (Figari Layus, 2013), la religión y el trabajo de duelo (Feierstein, 2015) y la espectralidad en la literatura (Mandolessi, 2013a y b). Si bien no utilizaremos aquí la categoría específica de "fantástico" -puesto que en los relatos testimoniales analizados no hemos encontrado sus figuras específicas, señaladas con anterioridad-, estos aportes resultan sustanciales al brindar nuevas herramientas para pensar terror y desaparición, por un lado, y los modos -siempre abiertos e inacabados- de su puesta en sentido, por el otro.
} 
dicha experiencia. Nuevamente, dimensión material del avasallamiento y dimensión imaginaria confluyen en la (re)construcción y puesta en sentido de ese momento límite por antonomasia.

En su libro "Sueños sobrevivientes de una montonera. A pesar de la ESMA", Susana Ramus hace referencia, también, a cierto desdoblamiento. En su caso, bajo la forma de una extrañeza, en tanto dificultad de sentir-se ella misma sujeto de lo vivido durante el proceso de cautiverio y desaparición:

"Ni siquiera morir era fácil y vivir era incierto / dos años en esa zona oscura, en esa línea imprecisa entre la vida y la muerte. Solo sintiendo que ojalá un día más para ver a mi hija / un día más para estar más cerca de la vida, dan ganas de pensar que nada de eso fue real, que sólo fue una pesadilla. Cómo hacer para aceptar esa parte mía, cómo sentir que soy, que todo eso me estaba pasando a mí y que no había dos susanas sino solo una". (Ramus, 2000: 67).

La (propia) desaparición bordeando el campo de lo real, como ubicándose en el límite; y una mujer que se interroga en torno al cómo sentir-se parte. Precisamente, esto nos trae una dimensión sustancial al problema de estudio, enunciada en apartados anteriores: la del proceso de elaboración necesario que sostiene esa (re)inclusión del sujeto en su propia historia, un trabajo que permita incluir lo vivido ( $\mathrm{y}$ al yo de esa vivencia) en el campo de experiencia. Que esta última, en todo caso, no resulta evidente y aprehendible en sí misma.

Como señaláramos al introducir el caso de Carlos, el entrevistado hizo referencia a los momentos posteriores a su secuestro y a algunas situaciones relativas al cautiverio. En su relato, se refirió a un fuerte aislamiento durante el período que estuvo secuestrado; Carlos se recuerda solo en una habitación, aislado y custodiado. Y en nuestra conversación nos señalaba:

“E: [En relación al cautiverio] ¿Y cuánto tiempo duró más o menos?

R: (Con seguridad) Treinta y cinco días.

(...)

E: ¿Había algún guardia, vos...?

R: Había constantemente guardias y todos los guardias tenían una cruz blanca, muy grande... Un crucifijo, un crucifijo blanco pero... iinmenso! O sea, se ve que era en nombre de Dios.

E: Ajá, ¿vos podías ver en ese momento...?

$R$ : Eh, vos..., vos veías lo que..., cuando se agachaba alguien veías lo que, lo que le colgaba era el crucifijo" (Segundo encuentro, 16/05/2012).

Guardias con crucifijos blancos, "inmensos". ¿Es posible que los guardias portaran esos crucifijos? ¿Pero acaso importa, en términos de nuestro objeto, la pregunta sobre la veracidad fáctica y/o comprobable de lo testimoniado? Detengámonos en el sentido mismo que configuran estos significantes pues es allí -y no en la materialidad/factualidad de lo testimoniado- donde podemos vislumbrar la radicalidad de la experiencia, específicamente en lo que ella tiene de ominoso: crucifijos, esto es, no tan solo "cruces" como materialidad posible de la participación de la Iglesia Católica en el sostén ideológico del sistema represivo sino la remisión a un objeto cuya imagen refleja en sí misma la tortura de Jesús en la cruz, agonizando en su lecho de muerte; blancos -acaso sea 
ese el color de la "pureza", pretendida y al mismo tiempo perdida por quien la porta-, inmensos - una inmensidad que, pronunciada enfáticamente, parece remitirnos a la persistencia de una pesadez (tortuosa) de lo vivido más que la materialidad de ese objeto-; en suma, la cruz que incluye en sí misma la agonía de la muerte, la pureza que no es pureza, la inmensidad que aun persiste (pesada, tortuosa). En este sentido, nos preguntamos si es posible pensar estos significantes -y no otros- como metáforas de una cosa otra, que trasciende la materialidad de lo enunciado y nos remite, en efecto, a lo siniestro de la (propia) desaparición y su espacialidad: el recuerdo acuciante de "crucifijos blancos inmensos" anunciando ya no -0 no tan sólo- las vinculaciones de la Iglesia con el poder desaparecedor sino una presencia de lo "conocido" en la espacialidad del CCD que, desde el recuerdo difuso y la imagen (parcialmente) vedada por las propias condiciones del cautiverio, se evoca desde lo que en ella hay de ominoso ${ }^{21}$. Ahora bien, retomando nuestro acápite, nuestro enfoque no apunta a reconstruir en sí misma la materialidad del aniquilamiento y el sistema clandestino de desaparición sino a un sentido de verdad que se sostiene, también y fundamentalmente, en la instancia subjetiva. Esto permite recuperar la palabra del sujeto en su singularidad y atender a los múltiples sentidos construidos en tanto modos de lidiar con aquello propio del límite ${ }^{22}$. En este sentido, poco importa que esas enormes cruces hayan colgado efectivamente de los guardias; lo cierto es que así lo hacen en la rememoración y, con ello, le permiten al entrevistado (re)construir ese momento de soledad y vulnerabilidad absoluta que constituyó su cautiverio y desaparición y trazar a partir de allí una puesta en sentido de lo vivido en el CCD, inscribiendo su violencia radical constitutiva en el campo de experiencia.

En uno de nuestros encuentros, Silvia nos relataba detalles de su cautiverio en un CCD del Gran Buenos Aires donde permaneció detenida-desaparecida durante tres meses aproximadamente. En junio de 1977, su compañero y ella, que cursaba sus primeros meses de embarazo, fueron secuestrados. Luego de algunos días en cautiverio, él fue "trasladado" -asesinado- y su cuerpo permaneció desaparecido hasta que, en 2009, el Equipo Argentino de Antropología Forense -EAAF- encontrara e identificara sus restos. Al relatar su cautiverio en los momentos inmediatamente anteriores a lo que sería su liberación, la entrevistada identifica un hecho sugerente, cargado de sentido en su evocación; entonces, nos relata un sueño:

"Me acuerdo una vez, que llovía... ¡Era una tormenta infernal! Pero unos truenos, pero viste, que... (Con un tono muy dulce, tranquilo) $Y$ que entonces yo... soñé. Soñé. Dormía y soñé que venía mi mamá y que estaba entre las "cuchas',23, viste. Y que decía "Silvi, Silvi", y que yo le decía "No, mami, M17 decía-, M17 ${ }^{24 ”}$ (sonríe), bueno. $Y$ todo así. iYo estaba segura que mi mamá estaba ahí! Y de pronto un trueno me despierta, viste. iY era una angustia...! Bueno, era como que... Bueno.

\footnotetext{
${ }^{21}$ En particular, agradecemos los señalamientos realizados por la doctora Mahlke sobre la versión preliminar de este artículo, sustanciales para esta digresión.

${ }_{22}$ Nos apoyamos, entre otros, en los desarrollos de Laub (1992) y Jelin (2006), quienes enfatizan la dimensión subjetiva de la(s) verdad(es) del testimonio.

${ }^{23}$ La noción de "cucha" es usada frecuentemente para referir a los pequeños lugares en los cuales los prisioneros eran obligados a permanecer durante el cautiverio.

24 Luego del secuestro, y al momento de ingresar al CCD, usualmente se asignaba un número identificatorio a los prisioneros como supresión de sus nombres reales.
} 
(Recupera el tono, habla normalmente) La cosa es que al día siguiente de ese sueño y de ese trueno, viene gente. (...) Que había que, viste, no sé, ¿como en las escuelas cuando venía el inspector, que había que poner todo en orden y los chicos contestar bien?

(...) Y me dicen "si contestás lo mismo [que en el primer interrogatorio], te vas a ir". (Vuelve a hablar en pasado) Yo contesté. ¡No creía para nada que me dejaran ir! Yo ya había visto a todos. (...) Y a la noche vienen y me... dicen: "M17, te vas" (Segundo encuentro, 29/11/2011).

En el sueño, su madre parece buscarla y venir por ella. Y ese sueño es el que antecede, como de manera mágica, al momento de la liberación. A partir de entonces, la entrevistada comienza a narrar cómo fue la situación de su traslado fuera del CCD, su llegada al hogar familiar, el reencuentro con su madre y su abuela y la confirmación de que su compañero no había aparecido. En esa narración minuciosa y apesadumbrada, lo onírico y la realidad material del cautiverio y el alivio/dolor del reencuentro confluyen en el relato de ese momento crucial en que finalizaba -en términos de una temporalidad identitaria ${ }^{25}$ - su desaparición. $\mathrm{Y}$, a partir de aquí, nuestra conversación prosiguió en torno a cómo ella "nunca volvería a ser la misma". Ahora bien, además de nuestra entrevista, Silvia ha brindado testimonio en numerosas instancias (judiciales, orales $\mathrm{e}$, incluso, producciones documentales). Al consultar parte de esas otras fuentes ${ }^{26}$, advertimos que ese mismo sueño que antecedía a la liberación adquiría nuevas significaciones: a los días de ser liberada, su madre le cuenta sobre el proceso de búsqueda que ella misma había iniciado tras su desaparición. En ese momento Silvia advierte que, precisamente, aquella noche de tormenta en que la había soñado llamándola (buscándola) por entre las cuchas, su madre había estado efectivamente buscándola. En su evocación, con una especie de asombro ante la "casualidad", ese sueño y la búsqueda confluyen explicando, conjuntamente, el momento de la liberación; nuevamente, realidad y registro onírico se encuentran, aportando nuevos sentidos.

Pues bien, ¿cómo interpretar estos relatos? ¿Es posible tan sólo contraponerlos al registro factual de lo vivido y negarles, con ello, su propia legitimidad y/o veracidad? Siguiendo a Laub (1992), la aparente distancia entre la "objetividad" de lo acontecido y el modo de evocación del sujeto no deslegitima la "veracidad" de la palabra sino que habla, precisamente, del carácter liminal y traumático de esta experiencia. Si la experiencia límite de la desaparición rompe el sentido y las formas propias del lenguaje (Gatti, 2008), los modos posibles de simbolización y narración de lo vivido se desplegarán en múltiples y aparentemente contradictorias modulaciones; algunas más ancladas en una verdad fáctica, otras arraigadas en una verdad subjetiva. Pero todas ellas, de conjunto, confluyen en el proceso -siempre inacabado- de significar y decir aquello propio del límite. Volviendo sobre nuestro acápite, que

\footnotetext{
${ }^{25}$ Retomamos la distinción trazada por Castoriadis ([1975] 2003, 2: 77-78) en relación al tiempo en su dimensión identitaria -como puro ordenamiento lineal y cronológico sobre el que se configura la realidad social- y aquella vinculada a la significación - "tiempo imaginario" como ese devenir heterogéneo de la temporalidad que, lejos de organizarse en una sucesión lineal de momentos, alberga la posibilidad de la alteridad, de la ruptura y la continuidad, de la irrupción, la simultaneidad y lo discontinuo, de lo múltiple-. Pese a la liberación, y en términos del tiempo imaginario, podemos pensar que en el caso de la sobrevida se produce un entrampamiento que persiste, aun en "libertad".

${ }^{26}$ Al finalizar nuestros encuentros, Silvia nos compartió un video documental donde se narraba su historia.
} 
nos advierte acerca de la relevancia ya no de la literalidad material de lo acontecido sino de la posibilidad de testimoniar acerca de lo inimaginable -en el caso citado allí, el de la voladura de las chimeneas en Auschwitz-, el relato de los sobrevivientes -anclado, como vemos, en estos múltiples registros posibles- anuncian también una ocurrencia inimaginable para todos aquellos que se encontraban desaparecidos y recluidos en los CCD: el de la posibilidad de decir la (propia) desaparición y su (entonces, es decir, en el momento de su ocurrencia) imposible, esto es, el de la (re)aparición y posterior sobrevida.

En función de estas consideraciones, nuestra pregunta se reescribe: ¿de qué manera uno y otro registro se complementan y qué nos dicen, en ese encuentro, sobre la radicalidad de la experiencia del campo y sus consecuencias presentes? Ambas dimensiones del decir remiten a la fase clandestina de la serie de la desaparición temporal y posterior sobrevida -esto es, aquella que se inaugura con el momento del secuestro, continúa con la tortura y el cautiverio y concluye con la liberación del sujeto, trayendo en su propia formulación aquello propio de lo ominoso-, pero lo hacen de manera diferente. Las primeras construcciones de sentido suponen, fundamentalmente, un aporte al conocimiento sobre el hacer clandestino del poder desaparecedor, el destino de los detenidos-desaparecidos y la elaboración de la prueba jurídica, entre otras; en este sentido, nos remiten al lugar específico del sobreviviente como testigo y portador, por ello, de un saber particular y sustancial. El segundo nudo significativo, por su parte, nos aproximaría a una narración más permeable a la instancia subjetiva y los modos singulares, múltiples y heterogéneos que asume la significación. Esta dimensión "imaginaria" emerge, con especial énfasis, al intentar significar y decir los momentos posteriores al secuestro, la tortura y el cautiverio. $Y$ es que son, precisamente, los momentos que producirán el clivaje y la re-configuración en la propia vida del sujeto.

Por un lado, entonces, estos relatos nos remiten a los modos de elaboración de la violencia vivida pero, al mismo tiempo, nos invitan a repensar la noción de experiencia para asirla en su propio proceso de (re)construcción, esto es, recuperando conjuntamente la dimensión material de lo vivido y una instancia subjetiva que le otorgue (múltiples) sentido(s).

\section{A modo de cierre}

La experiencia de la desaparición temporal y posterior sobrevida refiere, por antonomasia, a procesos de deshumanización/desubjetivación sobre los que se monta la maquinaria del exterminio. Sin embargo, en términos de su rememoración y efectos presentes, esta experiencia trasciende los límites espacio-temporales establecidos por la materialidad del secuestro y/o de los CCD y así, desde un "haz de remisiones", se va nutriendo de otros sentidos. En esas nuevas significaciones, decíamos, comienza a vislumbrarse otra dimensión constitutiva de la experiencia, relativa a esa instancia "imaginaria" que instituye formas complementarias de aproximación al CCD y de decir el límite. Y es que, acaso, estas situaciones liminales sólo sean posibles de ser 
enunciadas y simbolizadas en un campo en tensión cuyos polos se configuran entre la búsqueda de un sentido pleno en torno a los procesos de deshumanización/desubjetivación y estas otras construcciones que escapan a una racionalidad posible ${ }^{27}$; acaso sólo sea posible (re)construir sentidos en torno al exterminio desde estas múltiples y heterogéneas formas de simbolización, rememoración y enunciación. Como emergente de la producción material de la violencia constitutiva del CCD, entonces, la experiencia de la desaparición y posterior sobrevida se moldea y entreteje en un proceso de largo plazo que incluye, también, su rememoración y puesta en sentido; así, partiendo del avasallamiento que le da origen, la misma es reconstruida desde estos otros sentidos. Sentidos agónicos que, fundados en el espacio último de la violencia arrasante del sujeto y el mundo de interrelación, emergen al mismo tiempo como construcciones anudadas por un sujeto y/o colectivo que, pese a todo, da sentido a su propia vivencia/existencia.

Esas modalidades de acción y creación -aun cuando fragmentarias y/o lábilesconfiguran grietas de esas pretensiones desubjetivantes del poder desaparecedor. Nos dice Laub (1992: 62) que la palabra testimonial -en un sentido que trasciende la instancia de denuncia para constituirse en un acto de subjetivación- rompe el cerco de la muerte, afirmando la propia vida y anunciando en ese mismo decir un acto de resistencia; en este sentido, la posibilidad misma de significar y nombrar la experiencia del campo, con todas las "lagunas" y/o dolores que implica, trae consigo formas afirmativas de la subjetividad; aquella que otrora fuera avasallada y vulnerada. Allí, en su palabra, se afirma el sujeto. Podemos decir, entonces, que si la situación límite de la desaparición produce un movimiento desubjetivante, la puesta en sentido, la (re)construcción de la experiencia desde el mundo de la significación avanza en una modulación contrapuesta, como subjetivación.

Este artículo se propuso explorar esos nuevos sentidos emergentes en la evocación/configuración de la experiencia de la desaparición y posterior sobrevida. "Experiencia", como vimos, no desde un sentido cerrado y evidente en sí mismo, sino desde su multiplicidad: asible en la materialidad del golpe subjetivo (y social) que produjo la tecnología de la desaparición en su espacialidad propia, el CCD, como así también desde los procesos de significación y puesta en sentido que la moldean, junto con las nuevas subjetivaciones que se ponen en juego. Ahora, ¿de qué subjetivaciones se trata? Sobre ello avanzaremos en futuros abordajes.

\footnotetext{
${ }^{27}$ Los desarrollos de Gatti (2008), relativos a las tensiones y distancias en los modos de narrar y significar al detenido-desaparecido resultan sugerentes en este sentido.
} 


\section{Bibliografía:}

(2001) ACTIS, M., ALDINI, C., GARDELLA, L., LEWIN, M., TOKAR, E., Ese Infierno. Conversaciones de cinco mujeres sobrevivientes de la ESMA, Ed. Sudamericana, Buenos Aires.

(2000) AGAMBEN, Giorgio, Lo que queda de Auschwitz. El archivo y el testigo. Homo Sacer III, Ed. Pre-textos, Valencia.

(2002) AGAMBEN, Giorgio, Medios sin fin, Editora Nacional Madrid, Madrid.

(1943) BETTELHEIM, Bruno, Individual and mass behavior in extreme situations, The Journal of Abnormal and Social Psychology, 38, volume 4, pp 417-452.

([1998] 2004) CALVEIRO, Pilar, Poder y desaparición: los campos de concentración en Argentina, Ed. Colihue, Buenos Aires.

([1975] 2003) CASTORIADIS, Cornelius, La institución Imaginaria de la sociedad. El imaginario social y la institución, Ed. Tusquets, Buenos Aires.

(2011) COLOMBO, Pamela, "Espacio y desaparición: los campos de concentración en Argentina", Isegoría, Revista de Filosofía Moral y Política, 45, pp 639-652.

(2013) COLOMBO, Pamela, Espacios de desaparición. Espacios vividos e imaginarios tras la desaparición forzada de personas (1974-1983) en la provincia de Tucumán, Argentina, Tesis Doctoral en Sociología, Universidad del País Vasco. Mimeo.

(2015) FEIERSTEIN, Liliana R., "Huellas religiosas y culturales en las representaciones, elaboraciones y duelos de la violencia en Argentina", en Liliana Ruth Feierstein y Lior Zylberman, Narrativas del terror en América Latina, Universidad de Tres de Febrero, Buenos Aires (en prensa).

(2010) FELD, Claudia, "El centro clandestino de detención y sus fronteras. Algunas notas sobre testimonios de la experiencia de cautiverio en la ESMA", Recordar para pensar. Memoria para la Democracia. La elaboración del pasado reciente en el Cono Sur de América Latina, Ediciones Böll Cono Sur, Santiago de Chile.

(2014) FELD, Claudia, "Apuntes para repensar la noción de 'campo de concentración' en el marco del sistema desaparecedor argentino. El caso de la ESMA", Ponencia presentada en el Seminario Internacional "Estudiar la memoria desde América Latina", Santiago de Chile, 1-2 de octubre de 2014, Mímeo.

(2013) FIGARI LAYUS, Rosario, "Contra la impunidad: Juicios por violaciones de derechos humanos en Argentina", paper presentado en el XXXI International Congress of the Latin American Studies Association: Towards a New Social Contract?, 30 de Mayo al 1 de Junio de 2013, Washington, DC.

([1919] 2006) FREUD, Sigmund, "Lo ominoso", Obras Completas, volumen XVII, Ed. Amorrortu, Buenos Aires.

(2007) FOUCAULT, Michel, La arqueología del saber, Siglo Veintiuno editores, Buenos Aires.

(2008) GATTI, Gabriel, El detenido-desaparecido. Narrativas posibles para una catástrofe de la identidad, Ed. Trilce, Montevideo. 
(1981) JACKSON, Rosemary, Fantasy. The Literature of Subversion, Methuen \& Co, London.

(2006) JELIN, Elizabeth, "La narrativa personal de lo invisible", en Carnovale (et. al.), Historia, memoria y fuentes orales, CeDInCl, Buenos Aires.

(1998) KAUFMAN, Susana, "Sobre violencia social, trauma y memoria", Trabajo presentado en Seminario Memoria colectiva y represión, Montevideo, Uruguay.

(2013) LAMPASONA, Julieta, "Desaparición forzada en Argentina: entre la desaparición y la sobrevida. O sobre la 'regla' y la 'excepción' en el despliegue de la tecnología de poder genocida", Aletheia, Revista la Maestría en Historia y Memoria de la FaHCE, V 3, N 6, La Plata, Argentina.

(1992) LAUB, Dori, "Bearing witness or the vicissitudes of listening", en Felman, Shoshana y Dori Laub, Testimony: Crises of witnessing in literature, psychoanalysis, and history, Routledge, New York.

(2012) MAHLKE, Kirsten (et. al,): "Dimensiones del terror y de lo fantástico en Argentina. Un enfoque interdisciplinario". Simposio "Narrativas del terror en América Latina", Congreso Internacional de Americanistas. Viena, Julio de 2012.

(2014) MAHLKE, Kirsten, "'All limits were exceeded over there': the chronotope of terror in modern warfare and testimony", en Schindel Estela y Pamela Colombo, Space and memories of violence. Landscapes of erasure, disappearance and exception, Palgrave Macmillan Memory Studies, London, pp 105-118.

(2013) MANDOLESSI, Silvana, "Nadie nada nunca: Saer y lo espectral", en Ilse Logie (ed.). Juan José Saer. La construcción de una obra, Universidad de Sevilla, Colección 'Escritores del Cono Sur', Sevilla, pp 139-152.

(2013) MANDOLESSI, Silvana, "Dos veces junio", artículo presentado en el Encuentro con Martín Kohan, Universität Konstanz, Konstanz, Alemania, 2 al 4 de Julio de 2013.

(2013) PEREZ, Mariana E., "Los murmullos: un análisis de las dimensiones fantásticas de la desaparición forzada en el teatro de la post-dictadura argentina", ponencia presentada en el Workshop Miradas sobre la memoria. Jornadas de discusión e intercambio (Konstanz - Córdoba), Archivo Provincial de la Memoria, Córdoba, Argentina.

(2013) PEREZ, Mariana E., "Luisa se estrella contra la ESMA. Teatro, espectros y duelo", ponencia presentada en el Simposio Internacional Arquitecturas afectivas. Lugares, políticas y culturas del duelo en América Latina, Universidad de Zürich, 6 al 8 de Junio de 2013. (1991) PUGET, Janine y KAËS, René (eds.), Violencia de Estado y psicoanálisis, Centro Editor de América Latina, Buenos Aires.

(2000) RAMUS, Susana, Sueños sobrevivientes de una montonera, a pesar de la ESMA, Ed. Colihue, Buenos Aires.

(2007) ROUSSEAUX, Fabiana, “¿Existe una ética para la representación del terror? Escritura en los bordes de una ausencia sin restos", en Lorenzano, S. y 
Buchenhorst, R. (eds.), Políticas de la memoria. Tensiones en la palabra y la imagen, Gorla, Buenos Aires.

(2013) SCHINDEL, Estela, Ghosts and compañeros: haunting stories and the quest for justice around Argentina's former terror sites, Rethinking History: The Journal of Theory and Practice, DOI: 10.1080/13642529.2013.85845.

([1993] 2001) SCOTT, Joan, “Experiencia”, La Ventana, № 13.

(1981) TIMERMAN, Jacobo, Preso sin nombre, celda sin número, Random Editores, Nueva York.

(2006) TODOROV, Tzvetan, Introducción a la literatura fantástica, Paidós, Buenos Aires.

(1999) VAN ALPHEN, Ernst, "Symptoms of discursivity. Experience, memory and trauma", en Mieke B., J. Crewe y L. Spitzer (eds.), Acts of Memory, University Press of New England, Hannover $(\mathrm{NH})$ y Londres.

(2009) VEGA MARTÍNEZ, Mercedes y M. C. BERTOTTI, "Las resonancias sociales de la violencia producida por los procesos de desaparición en un barrio periférico de San Miguel de Tucumán", en actas del XXVII Congreso de la Asociación Latinoamericana de Sociología (ALAS).

(2011) VILLANI, Mario y REATI, Fernando, Desaparecido, memorias de un cautiverio: Club Atlético, el Banco, el Olimpo, Pozo de Quilmes y ESMA, Biblos, Buenos Aires. 